\title{
The specialty of clinical genetics: European Society of Human Genetics survey
}

\author{
Rodney Harris, Judith A Rhind
}

In Spring 1991 the Board of the European Society of Human Genetics (ESHG) set up a working party to review manpower and training in medical genetics in the European Community and beyond. The present report reviews the results of the first phase including the official status and training of physicians in clinical genetics. Later phases will be concerned with the status and training of laboratory genetic workers whose role it is to develop and carry out cytogenetic, molecular, and other tests.

\section{The survey}

A network was established from each country of one or two informants whom we believed were well informed about manpower and training. We asked them to complete an initial and a supplementary questionnaire which addressed, among other things, the following:
(1) whether clinical genetics is formally recognised as a specialty, (2) the arrangements for appointing specialists and their current numbers, (3) whether a training programme had been established, how was it supervised, what are the current number of trainees, length and content of training, (4) whether there is a need for a common European diploma in clinical genetics.

\section{Results}

Tables 1 and 2 summarise the information given by informants for all EC and some nonEC countries and a precis of comments from each informant is given in the appendix.

Clinical genetics is officially recognised in only four EC countries (Germany, the Netherlands, Portugal, and UK) with a total of 171 specialists, and in six non-EC countries (Austria, Czechoslovakia, Finland, Israel, Norway,

Table 1 European Community countries: recognition of clinical genetics as a specialty and training programmes.

\begin{tabular}{|c|c|c|c|c|c|}
\hline Country & $\begin{array}{l}\text { Is specialty of clinical } \\
\text { genetics recognised? }\end{array}$ & $\begin{array}{l}\text { No of clinical } \\
\text { geneticists }\end{array}$ & $\begin{array}{l}\text { Is there a formal } \\
\text { training programme? }\end{array}$ & No of trainees & $\begin{array}{c}\text { Duration of } \\
\text { training (years } \ddagger)\end{array}$ \\
\hline Belgium & No & 0 & No & 0 & - \\
\hline Denmark & No & (14) & No & (3) & 9 \\
\hline France & No & (30) & Yes & 20 & 2 \\
\hline Germany & Yes & $\sim 50$ & Yes & 35 & 2 \\
\hline Greece & No & 0 & No & 0 & - \\
\hline Ireland & No & 0 & No & 0 & - \\
\hline Italy & No & 0 & No & 0 & 4 \\
\hline Netherlands & Yes & 34 & Yes & 11 & 4 \\
\hline Portugal & Yes & 32 & Yes & 4 & 3 \\
\hline Spain & No & 0 & No & 0 & - \\
\hline UK & Yes & 55 & Yes & 39 & 4 \\
\hline Total & $4 / 11$ & $171\left(215^{*}\right)$ & $5 / 11$ & $109(112 \dagger)$ & \\
\hline
\end{tabular}

* Includes 44 clinical geneticists from countries without formal recognition of the specialty.

† Includes 3 trainees from Denmark.

$\ddagger$ Not always clear whether includes time gaining paediatric or internal medicine experience.

Table 2 Non-European Community countries: recognition of clinical genetics as a specialty and training programmes.

Genetic Enquiry

Centre, Department of Medical Genetics, St Mary's Hospital, St Mary's Hospital,
Manchester M13 0JH. R Harris

J A Rhind

Correspondence to Professor Harris.

Received 15 July 1992 Accepted 27 July 1992.

\begin{tabular}{|c|c|c|c|c|c|}
\hline Country & $\begin{array}{l}\text { Is specialty of clinical } \\
\text { genetics recognised? }\end{array}$ & $\begin{array}{l}\text { No of clinical } \\
\text { geneticists }\end{array}$ & $\begin{array}{l}\text { Is there a formal } \\
\text { training programme? }\end{array}$ & No of trainees & $\begin{array}{l}\text { Duration of } \\
\text { training (years) }\end{array}$ \\
\hline $\begin{array}{l}\text { Austria } \\
\text { Czechoslovakia } \\
\text { Egypt } \\
\text { Finland } \\
\text { Hungary } \\
\text { Israel } \\
\text { Norway } \\
\text { Romania } \\
\text { Russia } \\
\text { Sweden } \\
\text { Switzerland }\end{array}$ & $\begin{array}{l}\text { Yes } \\
\text { Yes } \\
\text { No } \\
\text { Yes } \\
\text { No } \\
\text { Yes } \\
\text { Yes } \\
\text { No } \\
\text { No } \\
\text { Yes } \\
\text { No }\end{array}$ & $\begin{array}{c}4 \\
51 \\
(1) \\
10 \\
(28) \\
17 \\
23 \\
0 \\
(200) \\
14 \\
(10)\end{array}$ & $\begin{array}{l}\text { No } \\
\text { Yes } \\
\text { Yes } \\
\text { Yes } \\
\text { No } \\
\text { Yes } \\
\text { Yes } \\
\text { No } \\
\text { No } \\
\text { Yes } \\
\text { Yes }\end{array}$ & $\begin{array}{c}(10) \\
15 \\
16 \\
9 \\
0 \\
2 \\
5 \\
(7) \\
(25) \\
2 \\
?\end{array}$ & $\begin{array}{l}3 \\
3 \\
6 \\
5 \\
-2 \\
2 \\
5 \\
-2 \\
5 \cdot 5 \\
4\end{array}$ \\
\hline Total & $6 / 11$ & $119\left(358^{*}\right)$ & $6 / 11$ & $49(91 t)$ & \\
\hline
\end{tabular}

* Includes 239 clinical geneticists from countries without formal recognition of the specialty.
† Includes 42 trainees from countries without formal programmes.

Data are awaited from the following non-EC countries: Bulgaria, Yugoslavia, Poland, and Turkey. 
and Sweden) with 119 specialists. In seven EC and five non-EC countries there is no formal recognition, but 44 and 34 specialists respectively were reported to be working in these countries as, for example, paediatricians but also others including non-medical staff who offer clinical genetic services. Procedures for accreditation differ and in this first survey it is difficult to assess comparability between countries of the role and training of clinical geneticists.

Established training programmes in clinical genetics were reported by informants from five EC countries (France, Germany, the Netherlands, Portugal, and UK) and six non-EC countries (Czechoslovakia, Egypt, Finland, Israel, Norway, and Sweden) with a total of 109 and 49 trainees, respectively. In Denmark ad hoc arrangements add another three trainees. The reported duration of training varies from two years (France, Germany) to up to nine years (Denmark). There is general agreement about the skills required by clinical geneticists and consequently about the content of training programmes. In more than half the EC and non-EC countries respondents strongly support the establishment of a European diploma in clinical genetics.

\section{Discussion}

Although national surveys have been carried out (in Britain for example ${ }^{1}$ ), this is the first European survey of clinical genetics. It does, however, rely on the personal knowledge of only one or two informants in each country and future surveys will require further refinement, clarification, and amplification. In particular, the role of clinical geneticists in some countries is not clear in relation to paediatricians and other specialties and to non-medical scientists. It is emphasised that genetics is part of many specialties and clinical geneticists with their specific role (see below) do not replace this involvement of others.

Nevertheless the results are disturbing because they show how inconsistent are the specific clinical provisions for genetic patients and families, especially as recent years have seen enormous advances in the precision of genetic diagnosis both clinically and in the laboratory. These advances have greatly increased the ability of doctors to help individual persons and families with genetic and congenital disorders, but have also created potential ethical problems especially in connection with prenatal and population screening and with gene therapy. For these reasons it is important to identify the aims of genetic services in terms that leave no doubt about the commitment of clinical geneticists to the overriding importance of human autonomy. These aims have been defined in Britain ${ }^{2}$ as follows.

\section{AIMS OF MEDICAL GENETICS}

(1) The provision of reproductive options by appropriate tests, services, and counselling.

(2) The prevention of genetic disease and con- genital disability only if subjects are well informed and are free to accept or reject screening and prenatal diagnosis.

(3) Collaboration with other clinicians in the most effective management of patients.

(4) The pursuit of genetic research to expand the base of genetic knowledge.

(5) Teaching genetics to medical students and others and the provision of information to professionals and the public to increase understanding of the role and potential of genetics in health and disease.

\section{ROLE OF CLINICAL GENETICISTS}

The role and training of clinical geneticists were the subject of a Clinical Genetics Society working party in $1983^{3}$ which with subsequent experience identifies the need for well informed and experienced clinical geneticists who (often in collaboration with others) have the ability to diagnose a wide variety of inherited and dysmorphic disorders affecting any body system and at any age. Such clinicians must therefore have a firm basis in medical training, with special experience of paediatrics and relevant adult specialties including neurology. The clinical geneticist must be able to recognise the importance of genetic heterogeneity, the range of human normality, the stress caused by genetic disorders in families, and the ethical issues raised by abortion, genetic screening, confidentiality, and other issues. The clinical geneticist must be aware of both the power and the limitations of laboratory genetics and be capable of combining clinical, pedigree, and investigational data into risk estimates upon which individual persons and families can make fundamental decisions, particularly about procreation. The clinical geneticist must be able to communicate empathically and non-directively when counselling patients and must relate well to nurses and other clinical co-workers capable of extending support to families in the community. Because of rapid advances in genetic technology, the clinician in this field must retain flexibility and this is encouraged by involvement in research.

\section{TRAINING OF CLINICAL GENETICISTS}

Among informants in the present survey there was a wide measure of agreement about the important components of training for clinicians who wish to practise in genetics and which are consistent with the roles defined above. These training components include specialised clinical experience of patients with genetic disorders at all ages and additional general experience of paediatrics, internal medicine, and perhaps of other specialties. Counselling skills are vital and should be formally taught as should the ethical basis of genetics. Clinical geneticists require knowledge of basic and laboratory genetics and of risk estimation. Although local conditions may limit opportunities, research is widely accepted as an essential ingredient of training because of the flexibility of mind required in 
genetics in which new observations are incorporated into practice with bewildering speed.

\section{A EUROPEAN DIPLOMA IN MEDICAL}

GENETICS?

About half of all respondents in EC and in non-EC countries were 'strongly' in favour of a diploma and rather more than half believed that the European Society of Human Genetics should take an initiative in its organisation.

\section{Recommendations}

These findings show inadequate and inconsistent provision for clinical genetics in Europe, while little is known in Europe generally of the services and training available for laboratory genetics. The ESHG Board therefore recommended the following. ${ }^{4}$

(1) The creation of an expanded Working Party to include additional clinical, molecular, and cytogenetic members whose task it will be to discuss the role of specialist medical geneticists and their training with the possible establishment of common European diplomas in medical genetics.

(2) The following terms of reference. To establish and keep up to date a database of clinical and laboratory genetic services and training in Europe and adjoining countries. To make recommendations to EC and national governments to achieve official recognition and resources.

From the UK viewpoint, and from that of certain other states, on the eve of 1993 and the extension of the Common Market in jobs, there is a worryingly wide discrepancy in status and training of clinical geneticists. The discussions now going on in ESHG on the role and training of specialist clinical geneticists are of particular interest and it is hoped that other countries will emulate Germany, the Netherlands, Portugal, and UK in giving official recognition to medical genetics and defining the specialist qualifications which distinguish clinical geneticists from paediatricians and other clinicians on one hand and non-medical scientists on the other. A majority of countries appear to favour common European diplomas in medical genetics and, although these might be less popular where training is already well organised, there may be overall benefits in establishing common training recommendations for Europe.

We are grateful to Professor Peter Harper and to Dr A W Johnston for helpful discussions, to Professor Martinus Niermeijer for pre-piloting the questionnaire, and to the following respondents for their information: Professors Aula (Finland), Basopoulos-Kyrkanidou (Greece), Berg (Norway), Connor (UK), Czeizel (Hungary), Fellous (France), Fryns (Belgium), Ginter (Russia), Harper (UK), Haughton (Ireland), Kucerova (Czech Republic), Legum (Israel), Mattei (France), Maximillian (Romania), Mikkelsen (Denmark), Muller (Switzerland), Niermeijer (Netherlands), Olah
(Hungary), Passarge (Germany), Romeo (Italy), San Roman (Spain), Schmid (Switzerland), Schnedl (Austria), Tavares (Portugal), Temtamy (Egypt), Wahlstrom (Sweden).

1 Clinical genetic services in 1990 and beyond. A report of the Clinical Genetics Committee of the Royal College of Physicians. London: Royal College of Physicians, 1991

2 Harris R. Medical genetics. BMF 1991;303:977-9.

3 Role and training of clinical geneticists. Report of the Clinical


Genetics Society Wor
genics Society, 1983.

4 Recommendations of the Board of the European Society of Human Genetics on manpower and training in medical genetics. Eur $\mathcal{F}$ Hum Genet (in press).

Appendix Comments regarding clinical genetics received during 1992 European Society of Human Genetics Survey.

\section{A European Community}

Belgium (Professor J P Fryns). The Belgian Ministry of Health has not given formal recognition to the specialty although there are eight centres of medical genetics in each of which two or three full time specialists are active (mostly paediatricians, a few internists and clinical biologists). In addition each centre has one or more nurses with a special interest in genetics, together with non-medical specialists. There are no specific training posts or training in clinical genetics. Professor Fryns believes that it will be difficult to establish a common European Diploma as the situation is so different from country to country.

Denmark (Professor Margareta Mikkelsen). Clinical genetics is not yet recognised as a speciality but negotiations are now in progress which may be successful in two or three years time. Training is recognised to be inadequate, there are too few trainees, and manpower is a big problem with staffing of universities cut every year and no new positions becoming available. The Ministry of Health is responsible for reviewing manpower in clinical genetics although the head of the department chooses candidates for the speciality of clinical genetics.

France (Professors J F Mattei and M Fellous). The speciality of clinical genetics is not recognised, there are very few training supervisors, and too few centres for training. However, negotiations for accreditation are currently taking place and a report has recently been sent to the Minister of Health to show the need for medical genetics as a special qualification. The present situation is that geneticists are either clinicians, usually paediatricians, but may also be biologists, biochemists, or molecular biologists, and even non-medical research workers.

Germany (Professor E Passarge). The specialty of clinical genetics has recently (May 1992) been formally recognised. Training is not adequate (currently only two years). A longer period of training (five years) is planned from 1992/3 and negotiations are taking place to expand the whole field of genetics.

Greece (Assistant Professor Euterpe BasopoulosKYRKANIDOU). Clinical genetics is not recognised as a specialty and medical genetics is practised by scientists who have received most of their training as fellows or postgraduate students in other countries, mainly the USA or Great Britain. The Hellenic Association of Medical Genetics is currently working on a proposal for organising medical genetics centres throughout the country to include clinical geneticists. Professor Basopoulos-Kyrkanidou believes that European Community level action is required.

IRELAND (Professor Jim Haughton). There are no formally organised genetic counselling services and there is no accreditation separate from the United Kingdom. A Ministry of Health working party in 1988 recommended the establishment of three specialist clinical genetic counselling services in Dublin, Cork, and Galway to provide a comprehensive genetic service. 
Italy (Professor Giovanni Romeo). Clinical genetics is not officially recognised and there is no effective organisation responsible for training programmes. A national body for all universities approves all courses and being a university professor entitles you to be director of a School of Specialisation for Medical Genetics; thus a professor of biology can be director of medical genetics. There are about 100 persons in training, of whom approximately 30 to 40 are medical doctors or biologists. It is hoped that EC regulations may improve the situation as the existing training arrangements for clinical genetics are 'useless'. Professor Romeo strongly supports the idea of a European Diploma to help establish clinical genetics in each country: this could be organised by a European Board along the same lines as in the USA.

LUXEMBOURG. We have no information on clinical genetics in Luxembourg.

Netherlands (Professor M F Niermeijer). Clinical genetics was established as a specialty in 1987. Accreditation is by the Dutch Board of Medical Specialists, Board of Clinical Genetics, Dutch Association of Clinical Genetics which allocates the number of specialists within the current eight clinical genetic services. There is currently a total of 34 specialists in clinical genetics. In each service staff are organised for pre- and postnatal chromosome analysis (at least one clinical geneticist and one cytogeneticist), genetic counselling (including staff for psychosocial follow up), metabolic disease, and DNA studies. After qualifying in medicine and in addition to specialist training in clinical genetics, trainees are expected to obtain experience in diagnostic methods relevant to the study of genetic diseases in paediatrics, etc. Appointments are made by university committees and the clinical genetic service must be associated with a university hospital. The quality of training is assessed by a visiting committee of the Board of Clinical Genetics, by whom training and accreditation are closely monitored. Because the Dutch system is working well Professor Niermeijer does not support a European diploma although he believes that clinical genetics training in the Netherlands should be expanded with more emphasis on disorders of adulthood, screening programmes, and method of public information.

Portugal (Professor Amandio Tavares). Formal accreditation for clinical genetics was established in 1979 and is regulated by the Ordem dos Medicos, Lisbon. Selection of specialists is by a national committee appointed by each hospital. There are currently 38 persons accredited and approximately 15 genetic nurses and 30 laboratory scientists in the country. Before entering clinical genetics training, persons must have completed a two year residency (medicine, surgery, paediatrics, or obstetrics) but any other specialty may be considered suitable if this fits in with individual training needs. Accreditation is not dependent on a final examination and can be obtained after a prescribed length of training for specialisation consisting of two years full time with a third year part time. The supervisor must be a consultant and the main emphasis of training is clinical genetics and family counselling. Three hundred patients must be personally observed and followed under the supervision of a tutor. These patients must include 'diverse pathology'. It is desirable that trainees spend up to 12 months abroad, at an institution chosen by the tutor. The Committee for Genetics of the Ordem dos Medicos verifies the quality of the training. There are currently four trainees in the country. In spite of these clear training requirements, Professor Tavares reports that training arrangements in Portugal are inadequate owing to a deficiency in laboratory facilities and the small number of clinical genetics units. He moderately supports the idea of an ESHG diploma, but only after general issues of European diplomas have been fully discussed.

SPAIN (DR SAN RomaN). The speciality of clinical genetics is not recognised and there is no formal training programme. Dr San Roman strongly supports the establishment of a European Diploma in clinical gen- etics as a way to obtain recognition in each country of the speciality of clinical genetics.

United Kingdom (Professors P $S$ Harper and J M CONNOR). The specialty has been recognised for more than 10 years. Training post numbers are allocated by a joint planning advisory committee (JPAC) of the Department of Health, Medical Research Council, and universities based on the anticipated number of specialist posts becoming available each year owing to retirements and new posts. The number of new specialist posts is decided by availability of local funding although overall national targets thought desirable (currently two per million of population) are based on recommendations of the Royal College of Physicians of London (RCP). The appointment of individual specialists to permanent ('consultant') posts is by local committee with representation from hospital, university, general management, and the RCP. Training includes general professional training (three years) which is comparable in intensity to that received by paediatricians, internists, etc, before beginning higher specialist training (generally four years) in clinical genetics. This must include a period in one of the 18 approved centres which have at least two consultant clinical geneticists. These centres are regularly inspected to verify the quality of training. In Britain a general postgraduate clinical examination (membership of a Royal College) is taken at the beginning of genetic training and there is no 'exit' diploma to signal completion of training. Accreditation may be applied for at the end of training but is not essential for appointment to a permanent specialist appointment; the quality of the appointees is the responsibility of the appointment committees who, at the time of interview, rigorously evaluate the training received.

\section{B Non-EC countries}

Austria (Professor W SCHNEDL). Clinical genetics is officially recognised and accreditation is supervised by the Osterreichische Arztekammar. Although accreditation does not depend on a final examination, a person is eligible to become a specialist immediately after obtaining a diploma and following a prescribed period of training in clinical genetics. Legislation to improve all medical training is currently in preparation and this will probably affect the training of clinical geneticists. At present, trainees in clinical genetics must have completed training in obstetrics, dermatology, internal medicine, paediatrics, or neurology/psychiatry. Thus, the diploma of a specialised clinical geneticist can only be obtained in addition to a diploma in one of these specialities. The specialist training in clinical genetics consists of two years of theoretical and laboratory education and one year of clinical experience, three years in total. There are no limits on the number of specialists and there are currently four accredited. There are currently 10 enrolled trainees in clinical genetics and nine trained supervisors. There are three approved training centres in Wien, Graz, and Innsbruck. Professor Schnedl would strongly support a European diploma organised by the ESHG.

Czech Republic (Professor M Kucerova). Clinical genetics is officially recognised. Specialists are allocated and monitored by Post-Graduate Institute Chairman of Genetics. Numbers are determined on the basis of one geneticist per 1 million inhabitants. Some of the components of training are covered in earlier medical training followed by three years' specialist training in clini$\mathrm{cal}$ genetics. Trainees are assessed by a committee and by examination with the award of a diploma. $\mathrm{Dr}$ Kucerova feels that the Czechs must "catch up with the level of European countries" and she is moderately supportive of a European diploma if it would help with lack of resources. She would accept a consensus in favour of this being arranged by ESHG with the agreement of the Czech Ministry of Health.

Egypt (Professor S Temtamy). The speciality is "not yet well accredited", as a person is eligible to seek accreditation after obtaining a $\mathrm{PhD}$ and there are no 
limits on the number of specialists. However, there are currently only two accredited persons, one $\mathrm{PhD}$ and one MD. The department in which the specialist will work is responsible for selection in consultation with the department in which the person was registered for training. The system is controlled by a government committee through the National Research Centre. Candidates from the National Research Centre are graduates of medical or dental schools or of the faculty of science. Professor Temtamy in the Al Shams University closely supervises trainees in clinical genetics for patient evaluation, investigations, and counselling and the training programme for clinical geneticists is taken in common with paediatrics. The recommended training programme consists of two years of basic courses in the university, with attendance on clinical rounds in the wards and clinics of the university hospitals and in the genetics clinics. In addition, a two year Masters thesis and a three to four year $\mathrm{PhD}$ thesis are prepared. This may total 11 years of training. The university in which registration is done approves the training programme. The quality of training is assessed by examinations, clinical, oral, and written, and a review of techniques. However, Professor Temtamy reports that training arrangements are not standardised and it is possible to become accredited without adequate clinical experience and the appropriate roles of clinical and non-clinical geneticists may not be distinguished. Training supervisors do not have formal training or degrees in clinical genetics and do not need to be approved. Although medical geneticists do not have uniform background and training, Professor Temtamy stresses that each has a valuable role in a team. Professor Temtamy supports the idea of a genetic education task group for Europe and the Middle East and strongly supports a European diploma. She suggests that courses might be organised by ESHG with a well defined syllabus, textbooks, and video tapes illustrating techniques, to be distributed to appropriate institutes affiliated with approved foreign centres. She also recommends continuing education courses for staff to update their knowledge.

Finland (Professor P Aula). Medical genetics was established in 1981, and since 1986 all medical specialisations have been carried out by the medical faculties of the universities although there are currently only 13 clinical geneticists. Three medical schools (Helsinki, Turku, and Oulu) have a medical genetics specialist curriculum. There are a limited number of training positions (currently five). Training consists of one year pre-training in any of the major clinical fields (paediatrics, obstetrics, internal medicine), two years working in the clinical genetics unit (genetic counselling, diagnostic consultations, prenatal diagnosis), and two years' laboratory work performing chromosome studies and DNA diagnostics.

Hungary (Professors E Olah and A Czeizel). The specialty is not officially recognised, the education of specialists is not well organised, and much improvement is needed in the graduate and postgraduate training systems. Hungary does have a form of accreditation by the postgraduate training university in Debrecen and there is a total of six approved training centres with currently 25 persons working as clinical geneticists and a few experts qualified in special fields of clinical genetics, namely dysmorphology, genetic counselling, tumour cytogenetics, and prenatal diagnosis. Persons need several years' experience with publication activity and, following the department's recommendation, two experts give their opinion, which if satisfactory leads to the postgraduate training university awarding the qualification, which is not restricted to medical doctors. According to Professor Dr Czeizel this does not constitute specialisation for clinical geneticists or medical geneticists. Hungary needs specialisation for medical geneticists (mainly for work in genetic counselling clinics and in patient clinics). An ESHG European diploma would be strongly supported to "achieve an international professional level in genetic research and in education".
ISRAEL (Professor C Legum). The specialty is officially recognised and accreditation is the responsibility of the Israel Medical Association Medical Council. Assessment is based on a final examination prepared by an education committee of 'geneticists internists'. There is a total of five recognised training centres. There is a prerequisite for specialisation in paediatrics, obstetrics, or internal medicine. There are no limits on specialist numbers and at present there are 17 accredited clinical geneticists. Individual hospital committees appoint specialists from among candidates who have responded to advertisements of posts in the public letter of the Israel Medical Association. This association also supervises standards and is responsible for the examinations. There are currently two doctors enrolled as trainees within Israel. The recommended components of training in clinical genetics are six months of clinical genetics, six months of laboratory work, and one year optional, that is, a minimum of two years. The training supervisors are the heads of the five recognised training centres. Criteria for recognition of centres include a requirement for the following minimum activity levels: 200 consultations per year including prenatal diagnosis, 200 prenatal laboratory (amniocentesis and CVS) tests per year, 200 biochemical genetical tests per year (for example, AFP/ACHE), and the provision of a national molecular genetic service for at least one disease (for example, haemophilia, Duchenne). Assessment for medically qualified geneticists is by a written examination and all recognised centres are monitored by a committee appointed by the Israel Medical Association. There are sub-specialties including cytogenetics, molecular genetics, and genetic counselling which involve medical doctors, those with $\mathrm{PhD}$, and others. These are recognised by the Department of Health and the medical school department of genetics which provide complementary university based training programmes. The training period and candidacy are monitored by the Israel Medical Association for medical graduates and by the separate medical schools for non-medical personnel. The Department of Health certifies both medical and non-medical geneticists after having received their respective university recognitions. The Government certification amounts to licensing in order to deal with the public. In general Professor Legum believes that training is adequate within Israel with the exception of genetic counselling. $\mathrm{He}$ moderately supports the concept of a European diploma, but "we would prefer European recognition of Israel's licensing for purposes of postgraduate study in Europe".

Norway (Professor Kare Berg). Medical genetics has been a certified specialisation since 1971 . There is a total of 23 clinical geneticists currently accredited. All specialist posts are associated with one of the three regional centres. Appointments are made by the hospital in which the regional centre is located following recommendations made by the centre. There is an international training committee in each centre referring to an outside board in medical genetics set up by the Norwegian Medical Association. The training requirement is four years in clinical genetics and one additional 'side year' making five years in total. Basic genetics is strongly recommended. The candidates attend a series of lectures and after one year they are encouraged to take part in group teaching of medical students. Cytogenetics is obligatory for one year. It is considered 'desirable' to have a year in molecular genetics, and this is shortly to become obligatory. Most candidates spend three years in very active genetic counselling. Research cannot be made obligatory for training for specialisation in Norway. Participation in training courses is obligatory and paid for by funds belonging to the Norwegian Medical Association. Supervision is the responsibility of a certified specialist with at least five years training in the subject. All specialists in permanent posts in any of the three regional centres are eligible as supervisors. At present there are nine senior experts acting as supervisors; each has two trainees, according to general rules. Professor Berg notes that the criteria which must be met by 
institutions at which training takes place are not sufficiently firm and, for example, there may be only a restricted range of genetic patients and insufficient university contact. He believes that training should be strictly limited to centres with an adequate number and spectrum of genetic diseases. There should also be a requirement to undertake research and there should be an examination towards the end of training. Professor Berg does not support a common European diploma recommending that this should be organised on a regional basis, pooling countries with similar systems and practices such as the Scandinavian countries, and this would apply with particular force to Western European countries and previous Iron Curtain countries.

Romania (Dr Maximillian). Clinical genetics is not officially recognised as a speciality and at present training is limited to short courses on medical genetics for paediatricians and obstetricians. Paradoxically there is a doctoral programme in medical genetics, but this does not necessarily mean that students will work in a university clinic. There are plans to introduce a clinical genetics course at the Faculty of Medicine at the Ecologic University in 1994. Clinical cytogenetics and dysmorphology are of considerable interest but as with all aspects of clinical genetics the lack of a recognised speciality and facilities is inhibiting. Information sources in Romania are rare and medical journals are not generally available. There is a great need to establish contacts with other genetic centres and to meet each other. Romania is beginning to establish links with Belgium and France. The establishment of a European diploma would be strongly supported owing to the shortcomings in Romania and the rate of expansion of genetic medicine.

Russia (Dr E K GinTer, Moscow). There is no forma recognition of specialists in clinical genetics, although an examination must be taken to become a specialist, of whom there are approximately 200 at present. There are approximately 20 to 25 persons enrolled as trainee in clinical genetics in the country. Training for specialisation takes two years consisting of six months' obligatory basic theoretical genetics, one year's obligatory paediatrics, and six months' obligatory specific counselling training. Other components such as cytogenetics, biochemical genetics, research, and the use of computer diagnostic programs are considered desirable. The training supervisor usually has more than 10 years' experience within clinical genetics and there are approximately seven to eight training supervisors within the country. There are six approved training centres within Russia. There are three sub-specialities related to clinical genetics. These are recognised by the programme of training and subsequent appointment to relevant posts. Dr Ginter notes that the main problem with training arrangements is that there is no connection between training of specialists in clinical genetics and the practice of genetic counselling because there are two types of training in clinical genetics. The first, which has been described above, is proposed for specialists who will work in the institutes, hospitals, and clinics. The second is for specialists who are working in genetic counselling. Usually the latter have experience and were trained in paediatrics or obstetrics and gynaecology. For these doctors there is a special programme of training in the fields of hereditary pathology and genetic counselling. The duration of the course is three months and after an examination the physician receives a special certificate as a medical geneticist. This course is repeated every five years for each specialist. Dr Ginter moderately supports the concept of a European diploma organised by the ESHG. He would prefer for Russia that a diploma be organised by the Institute of Clinical Genetics, National Research Centre of Medical Genetics, Russian Academy of Medical Sciences.

SWEDEN (DR J WAHLSTROM). The specialty is recognised. Although there is a postgraduate examination in clinical genetics, this is not compulsory. Most training in clinical genetics is in house within the department and there are no formal means for verifying the quality of training. It is recognised that there is a need for improved training courses accredited by the National Swedish Social Welfare Board with whom this is currently being discussed.

Switzerland (Dr Muller and Professor W Schmid). Although clinical genetics is not yet formally recognised, specialist posts are available at five universities and application was made at the end of 1991 to establish an accreditation system. In the meantime the Swiss Society of Medical Genetics supervises training programmes with currently 10 specialists in clinical genetics accepted by the society nationally. At least four years are devoted to medical genetics training and a further one year in another specialty, generally internal medicine or paediatrics. Trainees are recommended to spend time abroad but only in centres which fulfil the criteria for a medical genetic centre. Appointment to specialist posts is the prerogative of each institution. A European diploma would be welcome to provide a common standard organised by the Council of Europe. 